\title{
THE IMPACT OF ALVEOLAR HEMORRHAGE ON LUNG FUNCTION TESTS
}

\author{
Alina V. DOBROTA ${ }^{1,2}$, Claudia L. TOMA ${ }^{2,3}$, Ionela N. BELACONI ${ }^{2,3}$, Miron A. BOGDAN ${ }^{2,3}$ \\ ${ }^{1}$ Clinical Emergency Hospital of Bucharest, Bucharest, Romania \\ 2 "Carol Davila" University of Medicine and Pharmacy, Bucharest, Romania \\ ${ }^{3}$ National Institute of Pneumology "Marius Nasta", Bucharest, Romania
}

Received 03 Nov 2020, Accepted 24 Nov 2020

https://doi.org/10.31688/ABMU.2020.55.4.09

\begin{abstract}
Introduction. Alveolar hemorrhage syndrome is a severe condition, with a high-risk of death. A timely diagnosis and therapy may be life-saving. The „gold-standard“ method for diagnosing alveolar hemorrhage is bronchoscopy with bronchiolo-alveolar lavage. Pulmonary function tests are useful to appreciate the severity of alveolar hemorrhage.

The objective of the study was to measure the impact of alveolar hemorrhage on lung function tests and to detect useful associations between Golde score value and the type of alveolitis with spirometry tests, lung diffusing capacity for carbon monoxide (DLCO) and carbon monoxide transfer coefficient (KCOc), and six minutes walking test (6MWT).
\end{abstract}

Material and methods. We conducted a retrospective study on a sample of 60 patients diagnosed with alveolar hemorrhage syndrome, hospitalized in The National Institute of Pneumology "Marius Nasta" Bucharest, Romania, between June 2010 and February 2019.

Results. The results of bronchiolo-alveolar lavage show that macrophage alveolitis is associated with moderate-severe alveolar hemorrhage syndrome, while neutrophilic and lymphocytic alveolitis are associated with mild to moderate alveolar hemorrhage syndrome. Pulmonary function tests (spirometry and complex

\section{Résumé}

L'impact de l'hémorrhagie alvéolaire sur les tests de la fonction pulmonaire

Introduction. Le syndrome de l'hémorragie alvéolaire est une maladie extrêmement grave, parfois avec un risque élevé de décès. Un diagnostic et un traitement rapides peuvent sauver des vies. La méthode standard d'or pour diagnostiquer l'hémorragie alvéolaire est la bronchioscopie avec lavage bronchiolo-alvéolaire. Les tests de la fonction pulmonaire sont utiles pour apprécier la sévérité de l'hémorragie alvéolaire.

L'objectif de l'étude était de mesurer l'impact de l'hémorragie alvéolaire sur les tests de la fonction pulmonaire et de détecter des associations utiles entre la valeur du score de Golde et le type d'alvéolite avec des valeurs de spirométrie, des mesures de la capacité de diffusion pulmonaire du monoxyde de carbone (DLCOc), le coefficient de transfert de monoxyde de carbone (KCOc) et le test de la marche de six minutes (6MWT).

Matériel et méthodes. Nous avons mené une étude rétrospective sur un échantillon de 60 patients diagnostiqués avec un syndrome d'hémorragie alvéolaire, hospitalisés à l'Institut National de Pneumologie "Marius Nasta" de Bucarest, Roumanie, entre juin 2010 et février 2019. 
respiratory tests) showed that only Tiffeneau index, maximal expiratory flow at $50 \%$ of vital flow capacity and DLCOc were influenced by the presence of moderate to severe alveolar hemorrhage. The degree of desaturation measured at the end of 6MWT did not correlate with the degree of alveolar hemorrhage severity.

Conclusions. An abnormal gas transfer is common in alveolar hemorrhage, an increase of DLCOc value being a sensitive marker for the disease.

Keywords: alveolar hemorrhage, Golde score, functional lung tests.

\section{Abbreviations list:}

BAL - bronchiolo-alveolar lavage

AH - alveolar hemorrhage

FVC - forced vital capacity

FEV-forced expiratory volume

IT - Tiffeneau index

MEF50 - maximal expiratory flow at 50\% of vital flow capacity

DLCOc - lung diffusing capacity for carbon monoxide

TLC - total lung capacity

$\mathrm{KCOc}$ - carbon monoxide transfer coefficient

$6 \mathrm{MWT}$ - six minutes walking test

\section{INTRODUCTION}

Alveolar hemorrhage (AH) syndrome is a severe condition, with a high-risk of death ${ }^{1}$. It can appear at any age, often associated with other diseases, such as vasculitis or mixed connective tissue disorders. AH may also be the initial manifestation of an underlying systemic disease $e^{2}$. The diagnosis of $\mathrm{AH}$ needs a bronchoscopy with bronchiolo-alveolar lavage. Bronchiolo-alveolar lavage (BAL) is used in clinical practice for the diagnosis of certain pulmonary diseases (Table 1) $)^{3}$. A normal BAL fluid contains heterogenous populations of macrophages and lymphocytes ${ }^{4}$. When BAL detects an AH syndrome, the severity of the hemorrhage is assessed by Golde score,

Table 1. Normal cells of the bronchoalveolar lavage (BAL) liquid ${ }^{5}$

\begin{tabular}{cc}
\hline Total cell count & $<13 \times 10^{6}$ \\
\hline Macrophages & $>84 \%$ \\
\hline Lymphocytes & $<15 \%$ \\
\hline Neutrophils & $<3 \%$ \\
\hline Eosinophils & $<0.5 \%$ \\
\hline Mast cells & $<0.5 \%$ \\
\hline Plasmocyte & $0 \%$ \\
\hline
\end{tabular}

Résultats Les résultats du lavage broncho-alvéolaire montrent que l'alvéolite macrophagique est associée au syndrome d'hémorragie alvéolaire modérée à sévère, tandis que l'alvéolite neutrophile et lymphocytaire sont associées au syndrome d'hémorragie alvéolaire légère à modérée. Les tests de la fonction pulmonaire (spirométrie et tests respiratoires complexes) ont montré que seuls l'IT, le MEF 50 et le DLCOc étaient influencés par la présence d'une hémorragie alvéolaire modérée ou sévère. Le degré de désaturation mesuré à la fin de 6MWT n'était pas corrélé avec le degré de gravité de l'hémorragie alvéolaire.

Conclusions. Un transfert de gaz anormal est une constatation caractéristique dans l'hémorragie alvéolaire, une augmentation de la valeur DLCOc est un marqueur sensible pour la maladie.

Mots-clés: hémorragie alvéolaire, score de Golde, tests pulmonaires fonctionnels.

that is based on the hemosiderin content of alveolar macrophages (Table 2).

Hemosiderin-laden macrophages (HLM) in BAL fluid were originally used as diagnostic biomarkers of alveolar hemorrhage ${ }^{6}$, the presence of more than 90\% Fe-positive alveolar macrophages (siderophages) confirms a severe AH syndrome ${ }^{4}$. The presence of $\mathrm{AH}$ affects the alveolo-capillary gas exchanges, with subsequent changes in spirometry results and complex respiratory tests.

Spirometry is the most common and widely used lung function test, that measures the ability to inhale and exhale air in relation to time. Spirometry is a screening test of general respiratory health and for evaluating subjects whose major complaint is

Table 2. Golde Score interpretation.

\begin{tabular}{cc}
\hline Normal values & $4-25$ \\
\hline $\begin{array}{c}\text { Mild alveolar } \\
\text { hemorrhagic syndrome }\end{array}$ & $25-100$ \\
\hline $\begin{array}{c}\text { Moderate alveolar } \\
\text { hemorrhagic syndrome }\end{array}$ & $100-300$ \\
\hline $\begin{array}{c}\text { Severe alveolar } \\
\text { hemorrhagic syndrome }\end{array}$ & $300-400$ \\
\hline
\end{tabular}


dyspnea? The main variables of spirometry are forced vital capacity (FVC) and forced expiratory volume (FEV), maximal expiratory flow at $50 \%$ of vital flow capacity (MEF 50) and Tiffeneau index (IT), that represents the FEV1/FVC ratio. Measurements of single breath carbon monoxide transfer factor (DLCOc) and transfer coefficient (KCO) are used widely in the diagnosis and monitoring of respiratory diseases ${ }^{8}$. DLCOc is part of the complex functional tests needed to assess the lung function and aims to measure the diffusion capacity of carbon monoxide through the alveolo-capillary membrane (Table 3).

Table 3. Severity and classification of DLCOc reduction ${ }^{9}$

\begin{tabular}{cc}
\hline Normal DLCO & $\begin{array}{c}>75 \% \text { of predicted value, up } \\
\text { to } 140 \%\end{array}$ \\
\hline Mild & $\begin{array}{c}60 \% \text { to lower limit of } \\
\text { normal }\end{array}$ \\
\hline Moderate & $40 \%$ to $60 \%$ \\
\hline Severe & $<40 \%$ \\
\hline
\end{tabular}

The six-minutes walking test (6MWT) is a simple test, that has been standardized by the American Thoracic Society ${ }^{10}$, to measure the distance a patient can walk on a flat surface within 6 minutes at his own pace, without speeding at the end of this test. The distance travelled in meters is noted, as well as the appearance of dyspnea, measured with the help of the Borg scale. The 6MWT is a tool for an indirect respiratory function assessment ${ }^{5}$. In order to detect a possible latent respiratory insufficiency, a desaturation at effort by more than $4 \%$ compared to the initial value is considered significant ${ }^{6}$. The predictive value of the 6MWT is limited because of the lack of appropriate standardization ${ }^{11}$.

THE OBJECTIVE OF THE STUDY was to measure the impact of AH on lung function tests and to detect useful associations between Golde score value and the type of alveolitis with spirometry tests, lung DLCO and carbon monoxide transfer coefficient (KCOc), and six minutes walking test (6MWT). Other parameter followed in our study was the presence of triad: hemoptysis, dyspnea and pulmonary infiltrates.

\section{Material AND MEthods}

We conducted a retrospective study on a sample of 60 patients diagnosed with AH syndrome.

Inclusion criteria: patients with diagnosis of $\mathrm{AH}$ syndrome, hospitalized in the National Institute of Pneumology "Marius Nasta", Bucharest, Romania, between June 2010 and February 2019. All patients included have signed an informed consent that they agree to be included in the research. The study was approved by the ethics committee of the Institute (registration number 849/15.01.2018).

Exclusion criteria: patients with incomplete information in the files; patients who did not sign an informed consent.

\section{Statistical analysis}

Statistical analysis was performed using SPPS 22.0 software for Windows PC. Frequency and percentage were used to describe nominal/ ordinal variables, average, standard deviation for scale variables (scale type). For the comparative analysis of ordinal variables such as $\mathrm{DLCOc}, \mathrm{KCOc}$, alveolitis type,

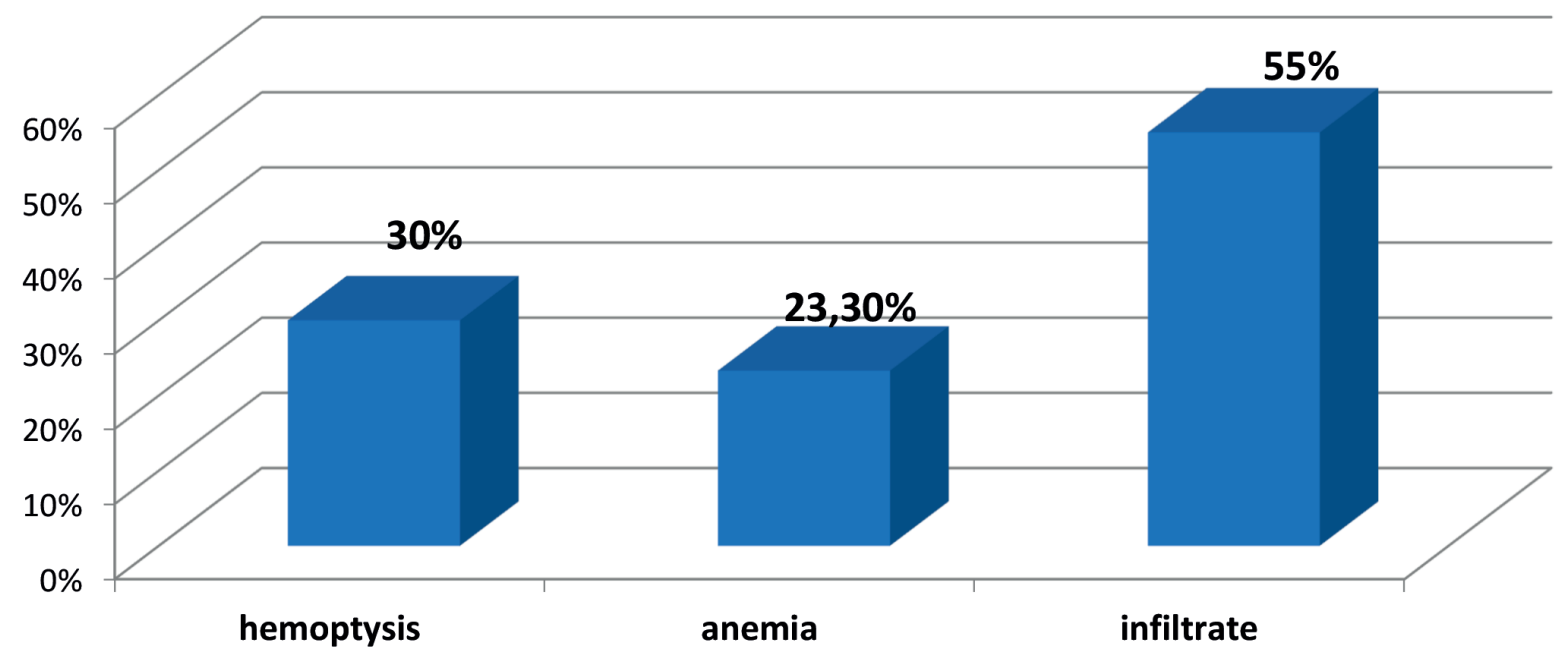

Figure 1. The distribution of patients according to the presence of hemoptysis, anemia and pulmonary infiltrates on chest X-ray. 
Table 4. Statistical correlation between alveolitis type and AH severity.

\begin{tabular}{|c|c|c|c|c|}
\hline & & \multicolumn{3}{|c|}{ Alveolitis type } \\
\hline & & $\begin{array}{c}\text { Neutrophilic } \\
n=28\end{array}$ & $\begin{array}{c}\text { Lymphocytic } \\
n=11\end{array}$ & $\begin{array}{c}\text { Macrophage } \\
n=15\end{array}$ \\
\hline \multirow{3}{*}{ Severity } & mild & $6 / 21.4 \%$ & $2 / 18.2 \%$ & $1 / 6.7 \%$ \\
\hline & moderate & $16 / 57.1 \%$ & $8 / 72.7 \%$ & $8 / 53.3 \%$ \\
\hline & severe & $6 / 21.4 \%$ & $1 / 9.1 \%$ & $6 / 40 \%$ \\
\hline
\end{tabular}

Chi-Square Tests

\begin{tabular}{lccc}
\hline & Value & diff & Asymp. Sig. (2-sided) \\
\hline Pearson Chi-Square & $4.430^{\mathrm{a}}$ & 4 & 0.351 \\
\hline Likelihood ratio & 4.707 & 4 & 0.319 \\
\hline Linear-by-linear association & 2.178 & 1 & 0.140 \\
\hline $\mathrm{N}$ of valid cases & 54 & & \\
\hline
\end{tabular}

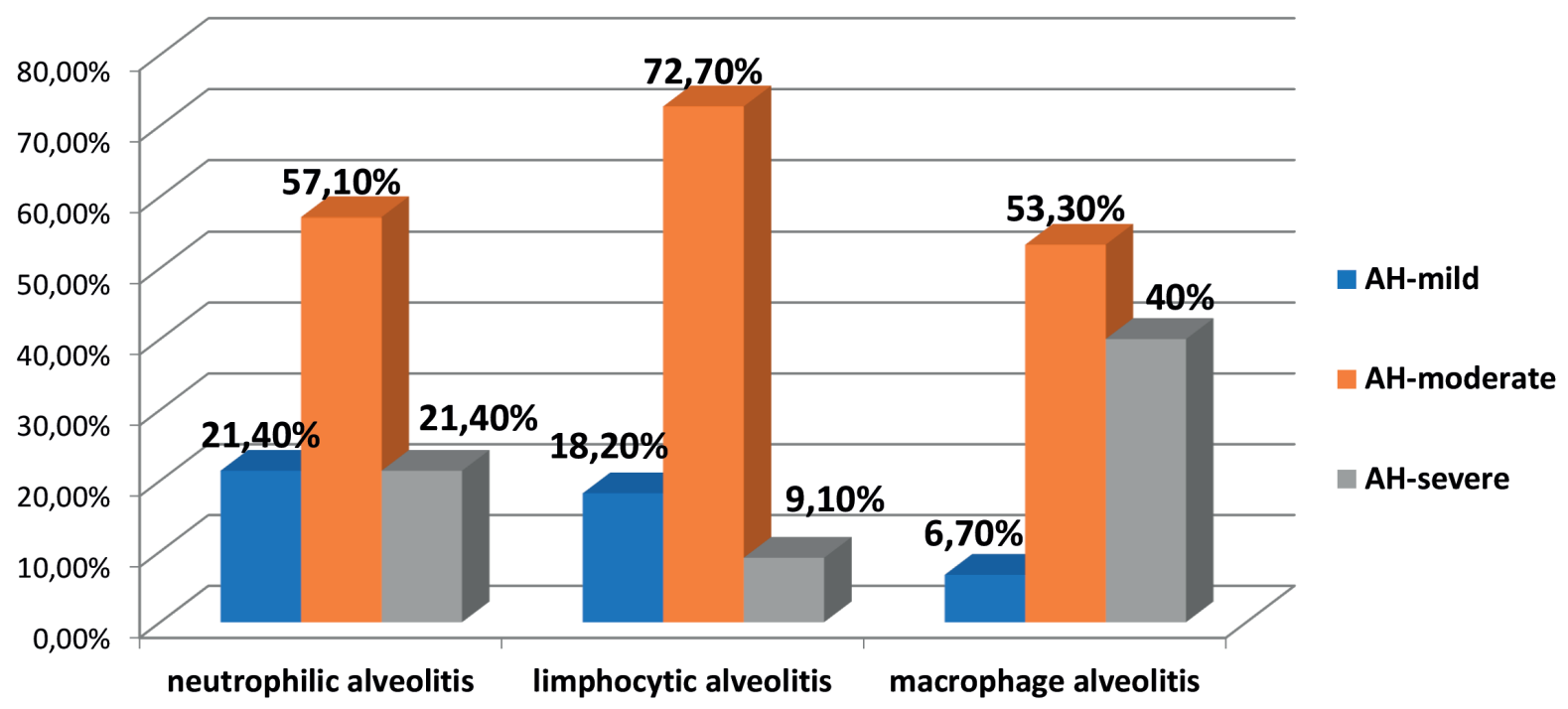

Figure 2. Correlation between alveolitis type and severity of AH.

Legend: AH-alveolar hemorrhage.

degree of desaturation depending on the type of alveolitis or the degree of severity, we used the Chi square test. The Kendall's tau and Gamma tests were used to assess the strength of the KCOc impact on the severity. The likelihood ratio was used to assess the chance of having a DLCOc effect on the severity in the absence of a statistically significant chi-square test value. To analyse the differences between the mean values of the spirometric variables, we used the one-way ANOVA test. The calculation of the eta factor allowed a differentiation of the effect according to the degree of severity. A p value $\leq 0.05$ was considered statistically significant.

\section{Results}

AH syndrome is characterized clinically and paraclinically by the presence of the triad: hemoptysis,
Table 5. Median values of the main spirometric variables.

\begin{tabular}{cc}
\hline FVC median value & $77.42 \pm 2.96$ \\
\hline FEV 1 median value & $72.5 \pm 2.65$ \\
\hline IT median value & $75 \pm 1.47$ \\
\hline MEF50 median value & $53.9 \pm 3.39$ \\
\hline
\end{tabular}

anemia and diffuse bilateral pulmonary infiltrates. Some patients do not present this classical triad, but an $\mathrm{AH}$ should be suspected when at least two of three criteria are present ${ }^{1}$. In our study, only one third of patients had hemoptysis and more than a half presented pulmonary infiltrates on chest X-ray (Figure 1).

Table 4 shows that macrophage alveolitis is associated with moderate-severe AH syndrome, while 


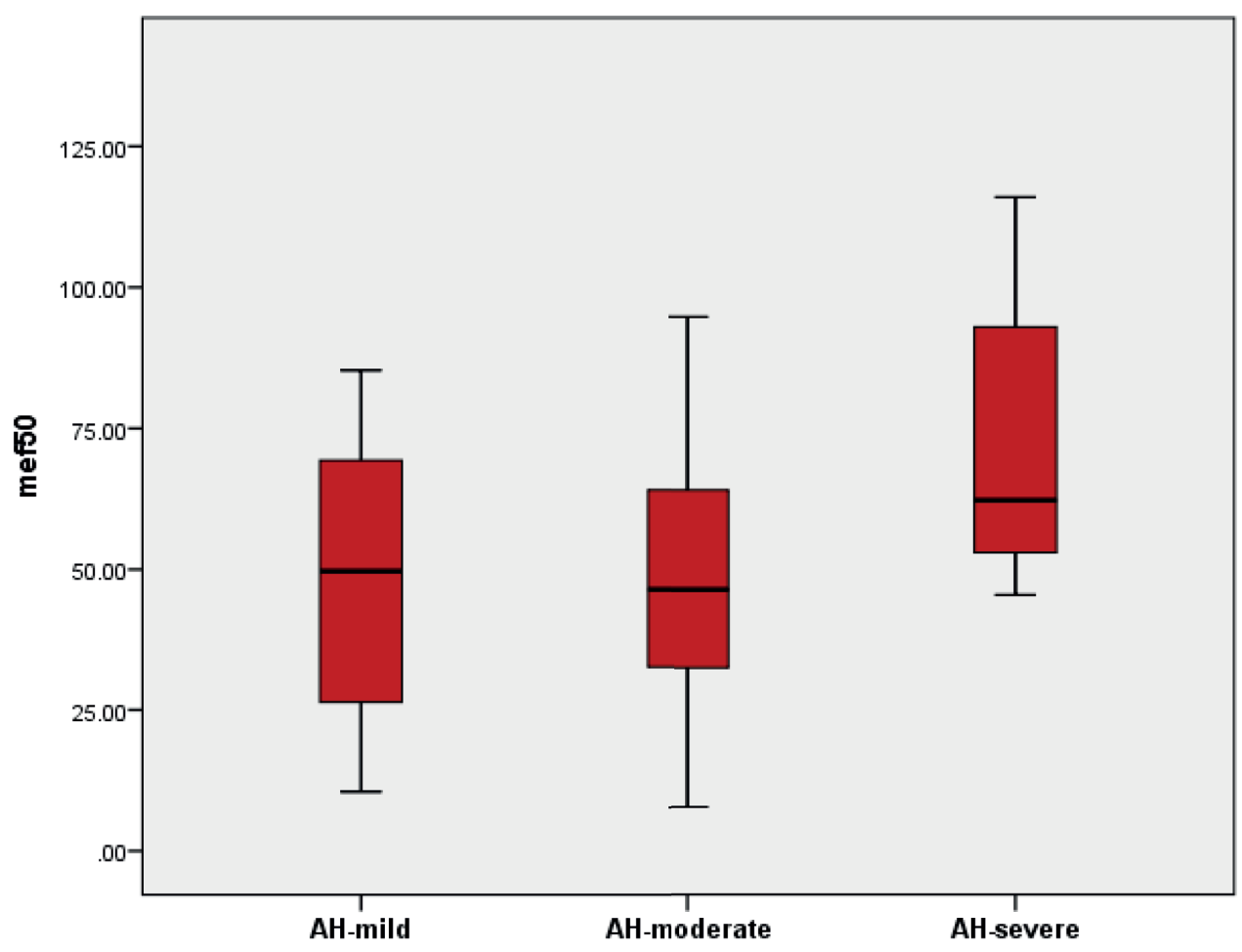

Figure 3. Statistical correlation between the severity of AH and MEF50 value.

Table 8. Tests of between-subjects effects - dependent variable: IT.

\begin{tabular}{cccccccc}
\hline Source & $\begin{array}{c}\text { Type III Sum of } \\
\text { Squares }\end{array}$ & $d f$ & Mean Square & $F$ & Sig. & $\begin{array}{c}\text { Partial Eta } \\
\text { Squared }\end{array}$ & Observed Power $^{b}$ \\
\hline $\begin{array}{c}\text { Corrected } \\
\text { Model }\end{array}$ & $654.542^{\mathrm{a}}$ & 2 & 327.271 & 2.748 & .073 & .091 & .521 \\
\hline Intercept & 236517.169 & 1 & 236517.169 & 1985.709 & .000 & .973 & 1.000 \\
\hline severity & 654.542 & 2 & 327.271 & 2.748 & .073 & .091 & .521 \\
\hline Error & 6551.031 & 55 & 119.110 & & & & \\
\hline Total & 333514.076 & 58 & & & & & \\
\hline Corrected Total & 7205.573 & 57 & & & & & \\
\hline
\end{tabular}

neutrophilic and lymphocytic alveolitis are associated with mild to moderate $\mathrm{AH}$ syndrome, but without significant differences, due to the small number of patients $\left(\chi^{2}(4)=4.4, \mathrm{p}=0.351\right)$ (Figure 2).

In the case of MEF50, an increase of the mean level is observed from approximately 48-49 units in case of AH syndrome (mild and moderate degree) to approximately 71 units (in case of severe degree) (Table 5). Application of the ANOVA-one way test indicates a statistically significant difference for $\mathrm{F}$ $(2.54)=4.01$ and $p=0.024$ (Tables 6,7$)$. Eta-partial square indicates a differentiation effect of about $13 \%(\eta 2=0.129)$, but a reduced test power of only 0.69. The differentiation is stronger in the case of moderate and severe $\mathrm{AH}$ syndrome, the mild degree determines a greater variability and a confidence interval of the average difference of MEF50 compared to the severe degree, with the upper limit close to zero (Figure 3).

In the case of IT, there is an increase in the mean level from about $71-73$ units (in the case of mild and moderate $\mathrm{AH}$ syndrome) and only about 8 units (in the case of severe degree). Application of the ANOVA-one way test indicates a statistically significant difference for $F(2.55)=2.74$ and $p=0.05$. Eta-partial square indicates a differentiation effect of approximately $9 \%(\eta 2=0.09)$ and a reduced test power of only 0.52 (Table 8). The differentiation is stronger in the case of moderate and severe AH syndrome (Figure 4).

In this study, most patients (40\%) had slightly lower DLCOc value and more than half of the patients had normal KCOc value (Table 9). 


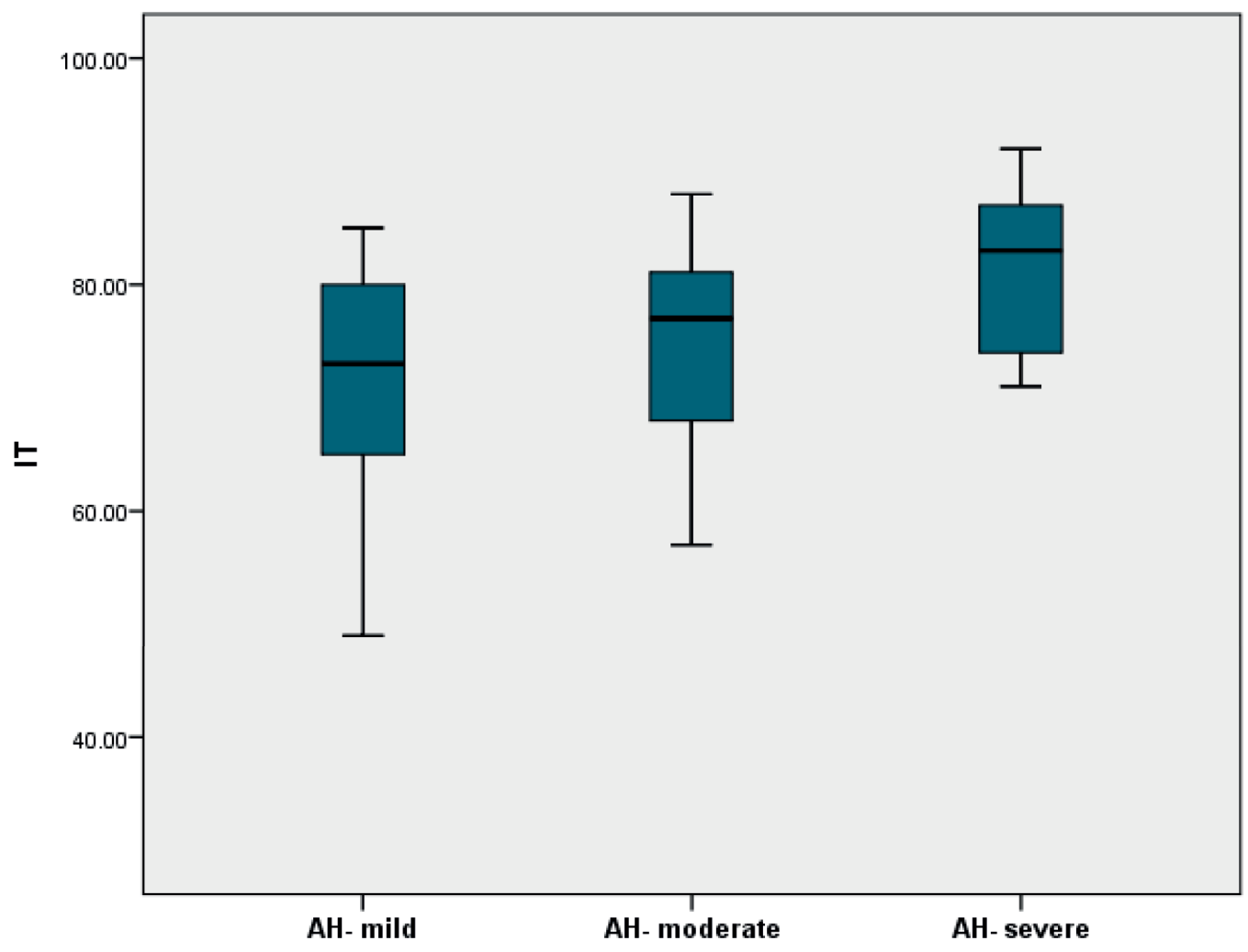

Figure 4. Statistical correlation between the severity of AH and IT values.

Table 9. Complex functional tests main parameters.

\begin{tabular}{ccc}
\hline Parameter & Value & Number of patients/ percentage \\
\hline DLCOc & Normal & $15(25 \%)$ \\
\hline & Slightly low & $24(40 \%)$ \\
\hline & Moderately low & $14(23.3 \%)$ \\
\hline KCOc & Severely low & $7(11.7 \%)$ \\
\hline & Normal & $33(55 \%)$ \\
\hline
\end{tabular}

Legend. DLCOc -single breath carbon monoxide transfer factor; KCO- transfer coefficient

Table 10. Correlation between the severity of AH and DLCOc values.

\begin{tabular}{ccccc}
\hline \multirow{2}{*}{ DLCOc value } & \multicolumn{3}{c}{ AH severity } \\
\cline { 3 - 5 } & & Mild & Moderate & Severe \\
& & $N=9$ & $N=36$ & $N=15$ \\
\hline \multirow{3}{*}{ dlcoc } & normal & $1 / 11.1$ & $9 / 25 \%$ & $1 / 6.7 \%$ \\
\cline { 2 - 5 } & slightly low & $4 / 44.4 \%$ & $12 / 33.3 \%$ & $2 / 13.3 \%$ \\
\cline { 2 - 5 } & moderately low & $3 / 33.3 \%$ & $5 / 13.9 \%$ & $4 / 26.7 \%$ \\
\cline { 2 - 5 } & Severly low & $1 / 11.1 \%$ & $10 / 27.8 \%$ & $8 / 53.3 \%$ \\
\hline
\end{tabular}

Chi-Square Tests

\begin{tabular}{cccc}
\hline & Value & $d f$ & Asymp. Sig. (2-sided) \\
\hline Pearson Chi-Square & $9.793^{\mathrm{a}}$ & 6 & 0.134 \\
\hline Likelihood Ratio & 10.333 & 6 & 0.111 \\
\hline Linear-by-Linear Association & 4.218 & 1 & 0.040 \\
\hline N of Valid Cases & 60 & & \\
\hline
\end{tabular}


The impact of alveolar hemorrhage on lung function tests - DOBROTA et al

Table 11. Symmetric measures of the statistical tests used

\begin{tabular}{|c|c|c|c|c|c|}
\hline & & Value & Asymp. Std. Error ${ }^{a}$ & Approx. $T^{b}$ & Approx. Sig. \\
\hline \multirow{3}{*}{ Nominal by Nominal } & Phi & 0.404 & & & 0.134 \\
\hline & Cramer's V & 0.286 & & & 0.134 \\
\hline & Contingency coefficient & 0.375 & & & 0.134 \\
\hline \multirow{3}{*}{ Ordinal by Ordinal } & Kendall's tau-b & 0.236 & 0.094 & 2.456 & 0.014 \\
\hline & Gamma & 0.359 & 0.140 & 2.456 & 0.014 \\
\hline & Spearman correlation & 0.278 & 0.109 & 2.202 & $0.032^{c}$ \\
\hline Interval by Interval & Pearson's R & 0.267 & 0.106 & 2.113 & $0.039^{c}$ \\
\hline \multicolumn{2}{|c|}{$\mathrm{N}$ of valid cases } & 60 & & & \\
\hline
\end{tabular}

Table 12. Correlation between the severity of AH and KCOc values.

\begin{tabular}{|c|c|c|c|c|c|c|}
\hline & & & \multicolumn{3}{|c|}{ severity } & \multirow{2}{*}{ Total } \\
\hline & & & mild & moderate & severe & \\
\hline \multirow{4}{*}{$\mathrm{KCOc}$} & \multirow{2}{*}{ normal } & Count & 2 & 24 & 7 & 33 \\
\hline & & $\%$ within severity & $22.2 \%$ & $66.7 \%$ & $46.7 \%$ & $55.0 \%$ \\
\hline & \multirow{2}{*}{ decreased } & Count & 7 & 12 & 8 & 27 \\
\hline & & \% within severity & $77.8 \%$ & $33.3 \%$ & $53.3 \%$ & $45.0 \%$ \\
\hline \multirow{2}{*}{\multicolumn{2}{|c|}{ Total }} & Count & 9 & 36 & 15 & 60 \\
\hline & & \% within severity & $100.0 \%$ & $100.0 \%$ & $100.0 \%$ & $100.0 \%$ \\
\hline
\end{tabular}

Chi-Square Tests

\begin{tabular}{cccc}
\hline & Value & df & Asymp. Sig. (2-sided) \\
\hline Pearson Chi-Square & $6.308^{\mathrm{a}}$ & 2 & .043 \\
\hline Likelihood ratio & 6.485 & 2 & .039 \\
\hline Linear-by-linear association & .491 & 1 & .484 \\
\hline N of valid cases & 60 & & \\
\hline
\end{tabular}

Table 13. AH severity and degree of desaturation at 6MWT.

\begin{tabular}{|c|c|c|c|c|c|c|}
\hline & & & \multicolumn{3}{|c|}{ degree of desaturation } & \multirow{2}{*}{ Total } \\
\hline & & & mild & moderate & severe & \\
\hline \multirow{3}{*}{ Degree of severity } & mild & Count & 0 & 0 & 2 & 2 \\
\hline & moderate & Count & 4 & 4 & 3 & 11 \\
\hline & severe & Count & 2 & 3 & 1 & 6 \\
\hline Total & & Count & 6 & 7 & 6 & 19 \\
\hline
\end{tabular}

Chi-Square Tests

\begin{tabular}{cccc}
\hline & Value & diff & Asymp. Sig. (2-sided) \\
\hline Pearson Chi-Square & $5.189^{\mathrm{a}}$ & 4 & .268 \\
\hline Likelihood Ratio & 5.526 & 4 & .237 \\
\hline Linear-by-Linear Association & 1.886 & 1 & .170 \\
\hline N of Valid Cases & 19 & & \\
\hline
\end{tabular}

Table 10 shows a higher proportion of the normal and slightly lower level of DLCOc in patients with moderate $\mathrm{AH}$, while in the case of severe $\mathrm{AH}$ the proportion of patients with moderate to severe low levels of DLCOc increases. By applying the Gamma test as a measure of prediction, we can say that the level of DLCOc knowledge improves the prediction for an increased level of AH severity with $35.9 \%(p=0.014)$ (Table 11).

From Table 12 we observe an increased proportion of low KCOc levels in patients with mild $\mathrm{AH}$, $77.8 \%$ compared to the normal level present in only 


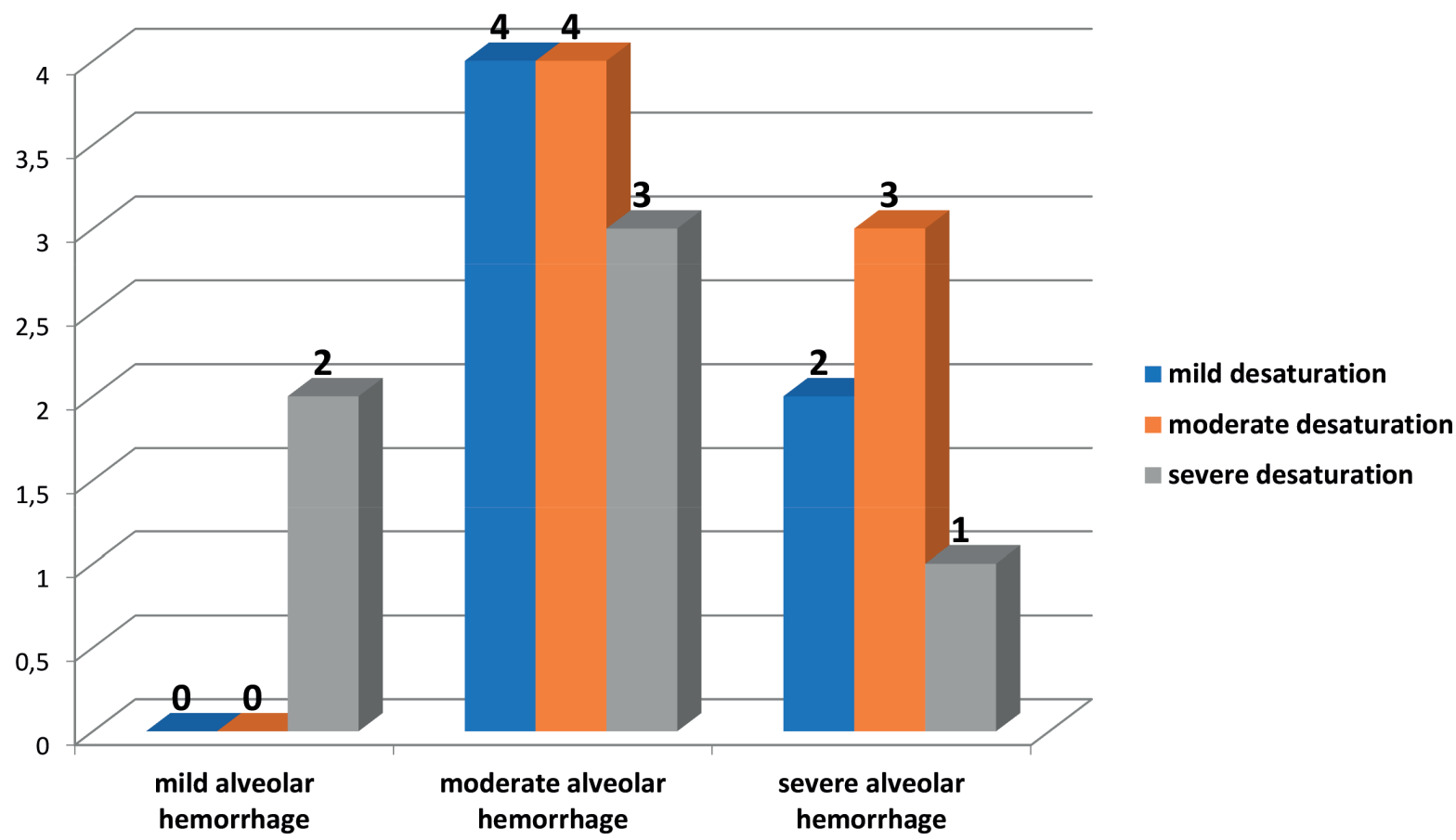

Figure 5. Correlation between the severity of AH and the degree of desaturation on 6MWT.

$22 \%$ of cases. In the group with moderate $\mathrm{AH}$, the inversion of the proportions is observed, $33.3 \%$ vs $66.6 \%$. The application of the Chi-square test indicates a statistically significant difference, $\chi^{2}=6.3, p$ $=0.43$. A low level of KCOc is not associated with a high degree of severity of $\mathrm{AH}$, while the normal level does not exclude an increased severity.

Out of a total of 60 patients, the 6MWT was performed only in 19 patients. Of these, 6 patients showed significant desaturation (more than $4 \%$ ) at the end of the test (Table 13). The degree of desaturation did not correlate with the degree of severity of $\mathrm{AH}\left(\chi^{2}(4)=5.18, \mathrm{p}=0.268\right)($ Figure 5).

\section{Discussion}

The typical presentation of $\mathrm{AH}$ is a triad of hemoptysis, anemia and pulmonary infiltrates on chest X-ray. In a study of 112 consecutive patients hospitalized for $\mathrm{AH}$, this triad was present only in $34 \%$ of patients, although most had severe diseases ${ }^{12}$. In another study, the $\mathrm{AH}$ triad was observed in $54 \%$ of patients, $67 \%$ presented with hemoptysis, $79 \%$ with anemia and all patients had new pulmonary infiltrates on chest X-ray at admission ${ }^{13}$. In our study of $60 \mathrm{pa}-$ tients, one third had hemoptysis and more than a half had pulmonary infiltrates on chest X-ray. To confirm the diagnosis, it is necessary to perform bronchoscopy with BAL. Technological advances have made flexible bronchoscopy a very effective tool in the diagnosis of many respiratory diseases, including conditions associated with $\mathrm{AH}$, and paved the way for many more technological break-through, both diagnostic and therapeutic $^{14}$. Flexible bronchoscopy with BAL was used to document $\mathrm{AH}$ in all patients included in the study. A rising red blood cells count in sequential BAL aliquots remaining bloody or becoming bloodier during the BAL procedure ${ }^{15}$ is considered diagnosis for the AH syndrome ${ }^{16}$. Macrophages may appear as quickly as within 2 days and may persist for several weeks ${ }^{17}$.

In the present study, BAL fluid cell counts, including the presence of siderophages, the main types of alveolitis (macrophage, neutrophilic and lymphocytic) and Golde score were analyzed and showed that macrophage alveolitis is associated with moderate-severe $\mathrm{AH}$ syndrome, while neutrophilic and lymphocytic alveolites are associated with mild to moderate AH syndrome, but without significant differences, due to the small number of patients. In a study of 94 patients diagnosed with alveolar hemorrhage, BAL fluid analysis showed a predominance of polymorphic neutrophils in specimens from patients with bacterial infections, while specimens from patients with fungal, viral, or Pneumocystis infections tended to have increased percentages of lymphocytes ${ }^{18}$. However, two important aspects remain unclear: one would be if the infection occurs at the same time as $\mathrm{AH}$, and the second if the infection is a precipitating factor or contributor to the occurrence of diffuse $\mathrm{AH}$. In patients already diagnosed with Wegener's 
granulomatosis or Churg-Straus syndrome, a high iron-positive macrophage count tends to be associated with active disease ${ }^{19}$.

To evaluate the impact of $\mathrm{AH}$ on lung function, there were performed several pulmonary function tests. FVC, FEV1, IT, MEF50, KCOc and DLCOC were measured by spirometry and plethysmography. Single-breath DLCOc value was adjusted for hemoglobin. All lung function testing was performed following the standards outlined by the American Thoracic Society/European Respiratory Society.

In a study evaluating the relationship between clinical disease characteristics, pulmonary function tests and high-resolution computed tomography (HRCT) findings in Wegener granulomatosis, 5 years after diagnosis ${ }^{20}$, one-third of patients had abnormal pulmonary function tests findings, consisting in reduced FEV1 value, reduced alveolar diffusion by $\mathrm{KCO}$ (transfer coefficient) being most common (24\%). In our study, FEV1 value did not correlate with the presence of severe $\mathrm{AH}$, but in the case of MEF50, an increased mean value is observed in moderate and severe $\mathrm{AH}$ syndrome.

In the presence of normal lung volumes and spirometry, the DLCO may be the sole abnormal test hinting to a pulmonary vascular disorder like chronic thromboembolic disease, pulmonary hypertension or other causes of pulmonary vascular obliteration ${ }^{21}$. Usually, the DLCOc value increases as the alveoli are distended, because the surface area for gas exchange increases and the alveolar-capillary membrane may become thinner ${ }^{22}$.

A high value of DLCOc has been reported in $\mathrm{AH}$ and attributed to increased carbon monoxide uptake by intra-alveolar red blood cells, so DLCOc measurement has been classically considered as a useful diagnostic test in $\mathrm{AH}$. However, a recent study of $\mathrm{AH}$ in Goodpasture's syndrome showed that DLCOc was increased in only a quarter of cases, and was reduced in half of them, probably as a result of ventilation/ perfusion mismatching ${ }^{23}$. Our study shows a higher proportion of the normal and slightly lower level of DLCOc in patients with moderate $\mathrm{AH}$, while in the case of severe $\mathrm{AH}$ the proportion of patients with moderate to severe low levels of DLCOc increases, because of the increased availability of hemoglobin within the alveolar compartment.

Monitoring the DLCOc may be useful in detecting exacerbations of $\mathrm{AH}$ in established cases, such as patients with idiopathic pulmonary hemosiderosis or antiglomerular basement membrane disease ${ }^{24}$. However, the relationship between iron deposition in the lungs and pulmonary dysfunction remains unclear ${ }^{25}$.

Although gas exchange measurements in interstitial lung disease, including lung pathology associated with $\mathrm{AH}$, usually are done by measuring the DLCOc, it is unclear whether estimates of gas exchange might be improved by measuring oxygen desaturation during 6MWT. A study of 130 patients diagnosed with sarcoidosis found that DLCOc is a good predictor of the absence of severe gas exchange impairment ${ }^{26}$, the same being valid in the case of $\mathrm{AH}$ syndrome. Also, a normal DLCOc value was a good predictor of the absence of severe desaturation during the $6 \mathrm{MWT}$ in sarcoidosis ${ }^{26}$. In our study, the degree of desaturation did not correlate with the degree of severity of AH. In another study of 50 patients diagnosed with pulmonary hypertension, a condition that may be associated with $\mathrm{AH}$ syndrome, it turned out that DLCOc was not related to exercise capacity, but to oxygen desaturation during exercise. TLC measurements did not provide any additional information in relation to the studied outcomes ${ }^{27}$.

The $\mathrm{KCO}$ is a measurement of the constant rate for alveolar uptake of $\mathrm{CO}$ during breath-holding in the single breath measurement of DLCOc at full inflation ${ }^{28}$. Some of the most common causes of a lower $\mathrm{KCO}$ are diseases with diffuse interstitial impairment, like pulmonary fibrosis, connective tissue diseases, vasculitis. KCOc values higher than the reference value could be present in conditions associated with $\mathrm{AH}$, like pulmonary oedema, congestive heart failure, mitral stenosis, Wegener's granulomatosis, systemic lupus erythematosus, idiopathic haemosiderosis ${ }^{28}$. In all these diseases, the severity of alveolar involvement varies and some normal alveoli survive and contribute to $\mathrm{CO}$ uptake ${ }^{28}$.

THE LIMITS OF THE STUDY. This study has some limitations because of a small number of patients and also because the results are influenced by the patients' ability to perform respiratory function tests correctly. Further studies are needed on a larger group of patients to obtain more statistically significant results.

\section{Conclusions}

Our study has found that the severity of the alveolar hemorrhage is correlated only with the values of the IT and MEF 50 in case of moderate or severe $\mathrm{AH}$. In terms of alveolo-capillary diffusion, the low value of DLCOc improves the prediction for an increased severity of AH by $35.9 \%$. Also, a low value of the KCOc is not associated with a high-degree of severity of $\mathrm{AH}$ but, at the same time, a normal value of KCOc does not exclude an increased severity of the disease. The degree of desaturation at 6MWT did not correlate with the degree of severity of $\mathrm{AH}$. 


\section{Author Contribution}

A.V.D, C.L.T,I.B, A.M.B equally contributed to the design of the study, to patient recruitment, statiscal analysis and writing of the manuscript. All authors were responsible for the collection and assembly of the articles/published data, and their inclusion and interpretation in this article. All authors contributed to the critical revision of the manuscript for valuable intellectual content. All authors have read and agreed to the published version of the manuscript.

\section{Compliance with Ethics Requirements}

„The authors declare no conflict of interest regarding this article"

"The authors declare that all the procedures and experiments of this study respect the ethical standards in the Helsinki Declaration of 1975, as revised in 2008(5), as well as the national law. Informed consent was obtained from all the patients included in the study"

"No funding for this study"

\section{Acknowledgements}

None

\section{References}

1. Lazor R. Alveolar haemorrhage syndromes. Orphan Lung Dis. 2011:15-31. doi:10.1183/1025448x.10007310

2. Lara AR, Schwarz MI. Diffuse alveolar hemorrhage. Chest. 2010;137(5):1164-1171. doi:10.1378/chest.08-2084

3. Gabe LM, Baker KM, van Beek EJR, Hunninghake GW, Reinhardt JM, Hoffman EA. Effect of segmental bronchoalveolar lavage on quantitative computed tomography of the lung. Acad Radiol. 2011;18(7):876-884.

4. Noble B, Du Bois RM, Poulter LW. The distribution of phenotypically distinct macrophage subsets in the lungs of patients with cryptogenic fibrosing alveolitis. Clin Exp Immunol. 1989;76(1):41-46.

5. Ciolan G, Magheran E, Grigorie V, Badescu C, Teleaga C. Alveolar hemorrhage syndrome - causes and diagnostic methods. Pneumologia. 2017;66(4):209-214.

6. Fukihara J, Taniguchi H, Ando M, et al. Hemosiderin-laden macrophages are an independent factor correlated with pulmonary vascular resistance in idiopathic pulmonary fibrosis: A case control study. BMC Pulm Med. 2017;17(1):1-6.

7. Delclaux C, Laveneziana P, Garcia G, Ninot G, Roche N, Morelot-Panzini C. [Pulmonary function testing of dyspnea complaint by the pulmonologist]. Rev Mal Respir. 2019;36(4):484-494.

8. Robson AG, Innes JA. Short term variability of single breath carbon monoxide transfer factor. Thorax. 2001;56(5):358361.

9. Pellegrino R, Viegi G, Brusasco V, et al. Interpretative strategies for lung function tests. Eur Respir J. 2005;26(5):948968.

10. Ruppel GL, Enright PL. Pulmonary function testing. Respir Care. 2012;57(1):165-175.
11. Lee J, Kim YH, Kang JY, Jegal Y, Park SY. Korean guidelines for diagnosis and management of interstitial lung diseases: Part 3. Idiopathic nonspecific interstitial pneumonia. Tuberc Respir Dis (Seoul). 2019;82(4):277-284.

12. De Prost N, Parrot A, Cuquemelle E, et al. Diffuse alveolar hemorrhage in immunocompetent patients: Etiologies and prognosis revisited. Respir Med. 2012;106(7):1021-1032. doi:10.1016/j.rmed.2012.03.015

13. Alexandre AT, Vale A, Gomes T. Diffuse alveolar hemorrhage: How relevant is etiology? Sarcoidosis Vasc Diffus Lung Dis. 2019;36(1):47-52.

14. Daniels JMA. Flexible bronchoscopy. JMA. 2017:1-18.

15. Grebski E, Hess T, Hold G, Speich R, Russi E. Diagnostic value of hemosiderin-containing macrophages in bronchoalveolar lavage. Chest. 1992;102(6):1794-1799.

16. Park MS. Diffuse alveolar hemorrhage. Tuberc Respir Dis (Seoul). 2013;74(4):151-162.

17. Fishbein GA, Fishbein MC. Lung vasculitis and alveolar hemorrhage: pathology. Semin Respir Crit Care Med. 2011;32(3):254-263.

18. Kahn FW, Jones JM. Analysis of bronchoalveolar lavage specimens from immunocompromised patients with a protocol applicable in the microbiology laboratory. J Clin Microbiol. 1988;26(6):1150-1155.

19. Schnabel A, Reuter M, Csernok E, Richter C, Gross WL. Subclinical alveolar bleeding in pulmonary vasculitides: Correlation with indices of disease activity. Eur Respir J. 1999;14(1):118-124.

20. Koldingsnes W, Jacobsen EA, Sildnes T, Hjalmarsen A, Nossent HC. Pulmonary function and high-resolution CT findings five years after disease onset in patients with Wegener's granulomatosis. Scand J Rheumatol. 2005;34(3):220-228.

21. Fitting J. Transfer factor for carbon monoxide: a glance behind the scene. Swiss Med Wkly. 2004;134:413-418.

22. Neder JA, Marillier M, Bernard AC, O'donnell DE. Transfer coefficient of the lung for carbon monoxide and the accessible alveolar volume: clinically useful if used wisely. Breathe. 2019;15(1):69-76.

23. Lazor R, Bigay-Game' L, Cottin V, et al. Alveolar hemorrhage in anti-basement membrane antibody disease: a series of 28 cases. Medicine. 2007; 86: 181-193.

24. Greening AP, Hughes JM. Serial estimations of carbon monoxide diffusing capacity in intrapulmonary haemorrhage. Clin Sci (Lond). 1981;60(5):507-12.

25. Priftis KN, Anthracopoulos MB, Tsakanika C, et al. Quantification of siderophages in bronchoalveolar fluid in transfusional and primary pulmonary hemosiderosis. Pediatr Pulmonol. 2006;41(10):972-977.

26. Chenivesse $C$, Boulanger S, Langlois $C$, Wemeau-Stervinou L, Perez T, Wallaert B. Oxygen desaturation during a 6-minute walk test as a predictor of maximal exercise-induced gas exchange abnormalities in sarcoidosis. J Thorac Dis. 2016;8(8):1995-2003.

27. Farkhooy A, Bellocchia M, Hedenström H, et al. Lung function in relation to six-minute walk test in pulmonary hypertension. Eur Clin Respir J. 2020;7(1).

28. Hughes JMB, Pride NB. In defence of the carbon monoxide transfer coefficient KCO (TL/VA). Eur Respir J. 2001;17(2):168-174. 